\title{
Research on the Construction of Modern Ecological Agriculture in Nanshan Ring Road of Xi 'an City
}

\author{
Tianmei Song \\ Xi 'an Peihua University
}

\begin{abstract}
Keywords: Nanshan loop, Ecological agriculture, Function, Construction.
\end{abstract}
\begin{abstract}
The Nanshan ring road of $\mathrm{Xi}$ 'an is endowed with advantaged tourism and agricultural resources, and has made a preliminary development driven by the consumption of the surrounding population. However, it is in the situation of insufficient planning, low-level duplication and more ecological damage. This paper puts forward that the ecological agriculture of Nanshan ring road should have the dual functions of production service and landscape culture, and on the basis of analyzing the resource advantages of relevant counties and districts 。 It proposes the construction of modern ecological agriculture of Nanshan ring road in $\mathrm{Xi}$ 'an from three aspects of planning, project and support.
\end{abstract}

\section{Introduction}

The No.1 document of the CPC Central Committee with the theme of "agriculture, rural areas and farmers" has gradually become a typical representative of the CPC Central Committee's attention to agricultural issues. The No. 1 document of the CPC Central Committee from 2014 to 2016 always insists on the fundamental status of China's agriculture and constantly promotes the supply-side structural reform of agriculture, so as to finally realize the development model of modern ecological agriculture that is green and efficient, resource-saving and environment-friendly. In March 2015, the national sustainable agricultural development plan (2015-2030) promulgated by the State Council proposed that agricultural development should establish ecological civilization concept and transform agricultural development mode. In October 2015, the most outstanding theoretical innovation at the fifth plenary session of the 18th CPC Central Committee was the "five development concepts", namely, "innovation, coordination, green, openness and sharing". Various provinces and regions of the developing of modern ecological agriculture has practical significance to optimize development layout, improve agricultural capacity, promote ecological circular agriculture development. Nanshan loop, based on the existing tourism resources and agricultural resources, vigorously develop modern ecological agriculture construction, which can promote economic development, employment, natural resources circulation, and realize win-win economic and ecological benefits.

\section{The construction background of modern ecological agriculture in $\mathrm{Xi}$ 'an Nanshan ring road}

\subsection{Ecological construction is the key content of "quality $\mathrm{Xi}$ 'an construction"}

Xi'an municipal party committee and government put forward the construction of "Quality Xi 'an" in the 2016 work report of $\mathrm{Xi}$ 'an government, which mainly includes the four fields of economy, culture, society and ecology. The government focus on "six big quality" to improve development of cities as economic development, which are urban governance, livable environment, opening to the outside world, people's life and government services, in order to realize the three big jumps of the economic strength, the income of urban and rural residents, extroverted degree, and to promote urban innovation drive, industrial competitiveness and comprehensive capacity, radiation motivating power and green development ability to lead a sharp increase from the above five aspects. At the same time, one of the five key actions of the government in promoting the supply-side structural reform is to implement high-quality supply action, adapt to personalized, 
diversified, safe and high-quality consumption demand, develop exquisite production, and strive to increase the effective supply of network information, cultural tourism, health and leisure and other service products.

\subsection{Xi'an Nanshan ring road is rich in tourism resources and agricultural resources}

Xi'an Nanshan ring line is China's traditional agricultural area, belonging to the continental monsoon climate zone with four clear seasons of coldness, warmness, dryness and wetness, and the free frost period reaches an average of 216 days a year, which is rich in light, heat, water resources, and suitable for agricultural production and diversified management. It's also rich in agricultural resources, with a variety of agricultural and sideline products, the most typical among which are apple, pear, kiwi, persimmon, walnut, and fish, cattle, sheep and other aquaculture.

\subsection{Analysis of the current situation of agricultural construction in Xi 'an Nanshan ring road}

In recent years, $\mathrm{Xi}$ 'an Nanshan ring road (Xi 'an section) is close to the city, scenery, road and water. Relying on abundant tourist resources and agricultural resources along the route, the agricultural park can flourish. The rapid development of modern agriculture along the Nanshan ring road in Xi 'an has also caused some problems. On March 31, 2017, in the project meeting, the city government in Qinling ecological environment stressed again and again to screening and treat the "four chaos" (disorderly and built, place, digging, deforestation, logging problems) which destroy the Qinling ecological environment. How to take into account the economic development and environmental protection, change the traditional agricultural development mode, and carry on the modern ecological agriculture construction is the question which the administrative authority should pay full attention to.

\section{The connotation of modern ecological agriculture construction}

Modern ecological agriculture is constructed by combining the principles of ecology and economics, emphasizing the application of modern scientific and technological achievements and modern management methods, aiming at achieving the maximum overall benefits of ecological economy, and forming a virtuous circle of ecology, economy and benefits. Ecological principle requires that human economic activities must follow the principles of environmental protection and economic development, resource development and sustainable utilization, and meanwhile the economic principle should ensure the rapid development of economic construction. Modern ecological agriculture is a "win-win" between ecology and economy. We should neither destroy the environment for the sake of development nor neglect development for the sake of protection. Development and construction should be carried out in accordance with ecological laws and in line with market demands, so as to generate economic benefits, thus promoting agricultural construction and ultimately realizing sustainable development of agriculture. The construction of modern ecological agriculture can be distinguished according to the emphasis on the industrial production and tourism. The other type is mainly leisure tourism, industrial production as a supplement. Nanshan ring line ( $\mathrm{Xi}$ 'an section) is rich in tourism resources and agricultural resources, which can be developed into modern ecological agriculture with both industrial production and tourism.

\section{Modern ecological agriculture construction concept of $\mathrm{Xi}$ 'an Nanshan ring road}

Modern ecological agriculture is constructed by combining the principles of ecology and economics, emphasizing the application of modern scientific and technological achievements and modern management methods, aiming at achieving the maximum overall benefits of ecological economy, and forming a virtuous circle of ecology, economy and benefits. Ecological principle requires that human economic activities must follow the principles of environmental protection and economic development, resource development and sustainable utilization, and economic principle should ensure the rapid development of economic construction. Modern ecological agriculture is a "win-win" between ecology and economy. We should neither destroy the environment for the sake 
of development nor neglect development for the sake of protection. Development and construction should be carried out in accordance with ecological laws and in line with market demands, so as to generate economic benefits, thus promoting agricultural construction and ultimately realizing sustainable development of agriculture. The construction of modern ecological agriculture can be distinguished according to the emphasis on industrial production and tourism. The other type is mainly leisure tourism, industrial production as a supplement. Nanshan ring line ( $\mathrm{Xi}$ 'an section) is rich in tourism resources and agricultural resources, which can be developed into modern ecological agriculture with both industrial production and tourism.

\subsection{Modern ecological agriculture construction concept of Xi 'an Nanshan ring road}

The ecological agriculture circle construction of Xi' an Nanshan should be designed based on the principle of "modularization and regionalization according to the relatively independent section to form modern ecological agriculture projects with a property of "point, line, and field" which are relative and characterized to each other. Based on the connotation of modern ecological agriculture construction and the development orientation, Xi'an Nanshan ring road (Xi'an district) could be developed into a direction of setting up section groups and integrating functions. As xi 'an is the tourist resource center of Nanshan ring line, it establishes a three-layer agricultural sightseeing belt according to the vertical distance-- near (Chang 'an district), middle (Lintong district, Huxian county) and far (Lantian county and Zhouzhi county). The districts and counties are relatively independent, each with its own characteristics, and closely connected, forming the layout of point-line scenic spots, providing a series of colorful projects, to fully tap the use of xi 'an consumer groups; Vigorously propagandize the existing famous scenic spot, strengthen the auxiliary scenic spot construction around the core scenic spot, broaden the scope of the scenic spot, increase the service function of the scenic spot, and form the layout of the scenic spot.

\subsection{The concept of supporting conditions for the construction of modern ecological agriculture along the Nanshan ring road in $\mathrm{Xi}$ 'an}

\subsubsection{Strengthen law enforcement}

The 32nd session of the standing committee of the 12th shaanxi provincial people's congress voted to adopt the regulations on ecological and environmental protection in Qinling mountains, Shaanxi province (hereinafter referred to as the revised draft), which delimits the scope of prohibited development zones, restricted development zones and moderate development zones. Any unit or individual shall have the right to report or charge against any act that damages the ecological environment of the Qinling mountains. The regulations, which will come into force on March 1, 2017, apply to sports authorities at or above the county level in advance for the record of travel, mountaineering and other tourism activities organized and carried out in areas outside the scenic spots or without road access. From the perspective of legislation, we have already perfected the problem of having laws to follow. In the process of implementation, we should continue to carry out follow-up matters that must be followed by laws, enforced strictly, and prosecuted.

\subsubsection{Implementing scientific planning}

In the process of the ecological agriculture park planning and construction, we must realize the advance scientific planning, in front of the building need to $\mathrm{Xi}$ 'an counties of landforms, terrain, resource type, resource distribution, natural scenery, cultural factors related to folk do in-depth and sufficient research, and after repeated discussions, determine clear industry development orientation; During the construction period, we always adhere to the principle of optimal resource allocation, and constantly improve the construction planning in the process, so as to avoid the blind development. For the selection and determination of projects, more technical support should be given to help each county and district find the right combination of agriculture and tourism, highlight the characteristics, avoid blind repetition, and not in-depth resources mining.

\subsubsection{Expanding external publicity}

The development of modern ecological agriculture will also adjust the industrial layout of China's rural areas, transforming the traditional primary industry into the tertiary industry and service industry, effectively increasing local employment and increasing local farmers' income. It will not 
only solve the problem of surplus rural labor, but also encourage many young and middle-aged workers in the village to return home to work. The development of the natural landscape environment and human landscape environment provided by modern ecological agriculture can not only make urban residents forget the pressure of work, relax their body and mind and cultivate their soul, but also show the charm of nature to everyone and spread a new way of life featuring green, environmental protection, energy saving and low consumption. Districts and counties should actively expand external publicity, create a regional development atmosphere, attract multiple tourists, and help external forces for construction and use of benign training.

\section{References}

[1] Yan Yan and Yang Xiaomei, Study on spatial structure of agricultural tourism resources in the northern foot of Qinling mountains, Journal of Xidian University (Social Science Edition), vol.4, pp.106-113,2008.

[2] Dong Hongmei, Study on sustainable development of eco-tourism at the northern foot of Qinling mountain, Journal of Anhui Agricultural Sciences, vol.2, pp.928-929+932,2011.

[3] Song Xiuyun and Yan Yan. Study on the cognition and consumption preference of Xi 'an citizens on the tourism agricultural park at the north foot of Qinling mountains. Acta Agriculturae Jiangxi, vol.7, pp.135-137,2008.

[4] Wang Shuai and Wang Rui. DaQinling: The first "national central park". Shaanxi Daily,2009-03-18.

[5] Zhao Qiguo. Modern ecological agriculture and agricultural security. Science \& Technology and Economy, vol.1, pp.58-64,2004. 